\title{
Geomagnetic Variation Anomalies in Canada
}

\author{
K. WHITHAM \\ Dominion Observatory, Ottawa, Canada.
}

\begin{abstract}
Anomalies in geomagnetic variations in the Arctic Archipelago are first discussed. The gross characteristics of the Alert (Ellesmere Island) anomaly can be explained by a number of models involving a $100 \mathrm{~km}$ upheaval of the $1400-1500^{\circ} \mathrm{C}$ isotherm to within $25-30 \mathrm{~km}$ of the surface. The solution is not unique and may be in error by as much as $60 \%$. However the response parameters most useful have been clearly defined. Magnetotelluric investigations lead to unusually high conductivities and a large anisotropy as expected. However a detailed synthesis of the magnetic variation results with the magneto-telluric analysis has not proved possible. At the present time, no self consistent explanation is known, but recent aeromagnetic and other data do not support any compositional explanation.

The suppression of the vertical field fluctuations at Mould Bay, Prince Patrick Island has been investigated further and the finite areal extert of the anomaly to the east has been demonstrated. Negative heat flow experiments and seismic investigations are described and their consequences outlined. A summary of the experimental variation and magnetotelluric data, now being examined, is given. The latter again qualitatively confirms the existence of a gross conductor, but at the present time it is not known if this is thermal or compositional in origin.

Experiments by the University of Toronto and the Dominion Observatory in southeastern Canada are described, which show that, within a confidence level of $20 \%$, there are no gross anomalies in the region of Southern Ontario from London to Ottawa, or across the Logan fault in Western Quebec. However, work by the University of British Columbia indicates appreciable conductivity anomalies of a varied nature from Crescent Valley, in southern British Columbia to Lethbridge, in southwestern Alberta. Current investigations of a coast effect off Vancouver Island are also outlined.

It appears clear that considerable theoretical advances are necessary to clarify which, if any, of the unusual features found are related to abnormal temperatures in the upper mantle. Where an integrated geophysical approach has been attempted in Canada, no self consistent explanation has yet been found.
\end{abstract}

\section{Introduction}

A number of Canadian studies are described of spatial changes in the characteristics of the time variations in the geomagnetic field which have either been proved, or inferred, to be a consequence of lateral variations in electrical conductivity within the earth. The work of the Dominion Observatory in cooperation with the Polar Continental Shelf Project in two regions of the Arctic Archipelago of Canada is described with emphasis, wherever possible, on relating the unusual effects found with other geophysical variables such as the gravimetric field, aeromagnetic results, heat flow studies and so on, and with the regional 
geology. The conclusions are outlined which can be drawn at the present state of the experimental and theoretical investigations.

Experimental work in southern Ontario and western Quebec by the Uuiversity of Toronto is next described: this fails to reveal any appreciable anomaly, a result confirmed as a consequence of other studies by the Dominion Observatory. Studies undertaken by the University of British Columbia in British Columbia and Alberta are then outlined: these indicate, over one $400 \mathrm{~km}$ segment of a much longer profile, a variety of unusual effects attributable to unusual induction. However, up to the present time, these results have not been interpreted in terms of models which can be tested by further experimental work or by a comparison with other geophysical variables. A search for, and study of, a coastal effect by the University of British Columbia, in cooperation with the Dominion observatory, is then outlined: this study is still continuing, but preliminary results are outlined. Some results are presented from a small network of variometer stations in the auroral zone.

Finally the significance of the large number of results obtained in Canada is discussed. It should be emphasized that this review deals only with variations with periods exceeding a few hundred seconds. The latest review of Canadian experiments on the spatial variations of micropulsations is that of Duffus et al. (1962). The micropulsation amplitude effects are very complicated in regions where the local crustal structure becomes complex, but this can be understood in terms of skin-depth arguments. However an assessment of the significance of the longer period results in terms of upper mantle or lower crustal features becomes, as will be seen, increasingly difficult, but no valid alternative has yet emerged.

\section{Recent Studies on the Alert Anomaly in Geomagnetic Variations}

On northern Ellesmere Island, the magnitude, directional characteristics and frequency dependence of the anomaly have been reported to be in general agreement with the hypothesis of a large anomalous conducting body striking approximately northeast-southwest with its centre a short distance to the southeast of Alert (Whitham and Andersen, 1962; Law et al., 1963). Potential analyses, spectral analyses, and gravity and aeromagnetic evidence support this hypothesis, the latter two being consistent with the suggestion of a thermal rather than compositional origin.

Recently the theoretical basis for the interpretation of the Alert anomaly has been reexamined by Rikitake and Whitham (1964). Under the uniform horizontal inducing field approximation, the electromagnetic response of an infinite elliptical cylinder of infinite conductivity has been derived, and from this the response for the upheaval of a half-elliptical conductor from a highly conducting mantle. The results have been extended to consider an asymmetric upheaval of the conducting mantle. An exact solution, using the infinite conductivity approximation, has been obtained for the problem of the electromagnetic coupling between an infinite circular cylinder and an underlying conducting layer. A number of two dimensional models have then been tested against the admittedly sparse experimental data obtained on one profile perpendicular to the strike of the proposed Alert conductor, and it was found that certain difficulties in the earlier interpretation of Law et al. (1963) could be reduced. 
Thus, by taking into account the electromagnetic coupling, it was possible to obtain theoretical agreement with the experimental observations with the top of the cylindrical body lowered to a more reasonable depth of some 25 to $30 \mathrm{kms}$. Furthermore the calculations proved very useful in illustrating which parameters could be most simply interpreted. For example, it was shown that the maximum magnitude of the anomalous variation field was largely determined by the ratio of the rise of the conducting material to the depth of the undisturbed conducting mantle. Another parameter, which can be estimated experimentally and which it is very important to study, is the halfwidth of the anomalous field across the strike. The ratio of the half-width to the depth to centre has been studied: this is equivalent to the depth to the plane conductor, if a half-body lifted out of the mantle is considered. The ratio of the halfwidth to the horizontal width of the body at centre has also been studied for a number of geometrical models. The results obtained indicate that the ratio of the half-width to the width at centre increased rapidly for any type of model as the top of the body gets deeper as would be expected, and hence the practical use of such a parameter in interpretation is very doubtful. However, the ratio of the half-width to depth to centre is approximately similar within a given class of models and is obviously useful in placing further approximate conditions on acceptable models. The resolution, however, was found to be quite poor, the details of any hypothetical geometrical section distant from the surface being almost completely indeterminate from realistic surface experiments in the Canadian Arctic.

Rikitake and Whitham (1964) concluded that, considering the magnetic variations alone, a conductivity of $10^{-11} \mathrm{emu}$, corresponding to the 1400 or $1500^{\circ} \mathrm{C}$ isotherm, is required 25 to $30 \mathrm{~km}$ below Alert, the isotherm being required to rise $100 \mathrm{~km}$ over a lateral distance which could be substantially greater than $100 \mathrm{~km}$. Their theoretical work suggested that an expansion of all these distance parameters by about $60 \%$ would be acceptable in terms of the present accuracy of determination of the magnitude of the response, the half-width of the anomalous induced field and the potential analyses. It appeared that, in general, reasonably accurate determinations of the maximum magnitude of any effect and its half-width provide as much information as can be usefully used quantitatively in the present stage of the theory.

The available seismic data indicate that failure is not occurring at the present time in the region of North Ellesmere Island. However, it is quite conceivable that this could be reconciled to a body now cooling and that the tensional stresses exceeded the breaking strength in the late Mesozoic when faulting is known to have occurred, roughly parallel to the anomaly axis.

New experimental studies during the 1963 field season described by Whitham and Andersen (1965) using a coordinate system for magnetomater orientation parallel and perpendicular to the strike, are quite compatible with the hypo thesis that the two-dimensional structure is found approximately $150 \mathrm{~km}$ southwest of Alert. This result, based on several weeks of records from one station only, Lake Hazen, is the only known experimental data indicating an extension along strike, and fails to justify fully the implicit assumption in all the theoretical work, described above, that the scale length of the inducing field is less than the length of the two-dimensional body along strike. 
A more serious problem has been pointed out by Whitham and Andersen (1965) in their discussions of the results obtained from a magnetotelluric study in and near Alert during 1963. Despite the well known difficulties of working in permafrost areas, the field work near Alert has demonstrated the following magneto-telluric characteristics, which have been shown to be reproducible at two sites separated by several miles. The electric field was found to be very strongly confined to a direction nearly north-south, the confinement being much tighter than that of the magnetic vector in the northwest-southeast direction, and a strongly anisotropic situation was found with the electric field approximately in phase with the horizontal magnetic field for periods between 240 and $6000 \mathrm{sec}$, and the electric to magnetic field ratio constant and abnormally small $(0.126 \mathrm{mV} / \mathrm{km} / \gamma)$ in this period range. This very low field ratio over a period range extending to 100 minutes appears to be unique in the world. In the absence of experimental data showing the existence of a magnetic variation anomaly near Alert, the magneto-telluric data could have been interpreted in terms of a near-surface conductor with the extremely large height-integrated conductivity of about $6.3 \times 10^{-6} \mathrm{emu}$, and a very large, perhaps shape-induced, anisotropy. There is no geological or geophysical evidence for such an unusual near-surface conductor. Alert weather station is underlain by Lower Palaeozoic limestone, shale, and greywacke, and lies in a folded near-eugeosynclinal region, with an estimated $6 \mathrm{~km}$ or more of sediments to the basement (Christie, 1963). A major fault zone, the Lake Hazen fault zone, extends some 200 miles along the mountain front of North Ellesmere Island, but the Lake Hazen plateau is believed to constitute a rigid block, last folded in Palaeozoic time. From the results of electrical logs from Winter Harbour No. 1 hole on Melville Island, the conductivity of these ancient sedi ments is found to be about $1.6 \times 10^{-13} \mathrm{emu}$, giving a maximum corresponding height integrated conductivity of $9 \times 10^{-8}$, or seventy times too small. There is no evidence in this old sedimentary basin for the existence of some 200 to $600 \mathrm{~m}$ of saturated salt solutions, or $6 \mathrm{~km}$ of salt-water sands. Earlier Whitham and Andersen (1962) reviewed the indirect evidence against extensive basement mineralization: very extensive graphitic or sulphide bodies would be required to account for either the magnetic or the magnetotelluric results. Recently additional airborne magnetometer flights in this region have been made by Serson, Hannaford and Haines of the Dominion Observatory, as part of the three-component regional aeromagnetic survey of Canada. Figure 1 shows the profiles obtained from plotting the computed five-minute averages in the total magnetic field intensity, after subtraction of arbitrary smooth regional fields. The profiles support the conclusion drawn by Whitham and Andersen (1962) from the earlier aeromagnetic profiles of Ostenso. A striking reduction in the amplitude of the magnetic total field intensity anomalies is seen over the geosyncline, with particularly flat profiles observed over that part of the syncline covered with the younger sediments of the Sverdrup Basin. The absence of large Imagnetic anomalies near the continental slope immediately north of Alert, in contrast to the results over north Greenland and northwestern Ellesmere Island, may also be significant. It is clear that neither the gravity data nor the aeromagnetic data suggest extensive basement mineralization as the source of a large near-surface conductor. 


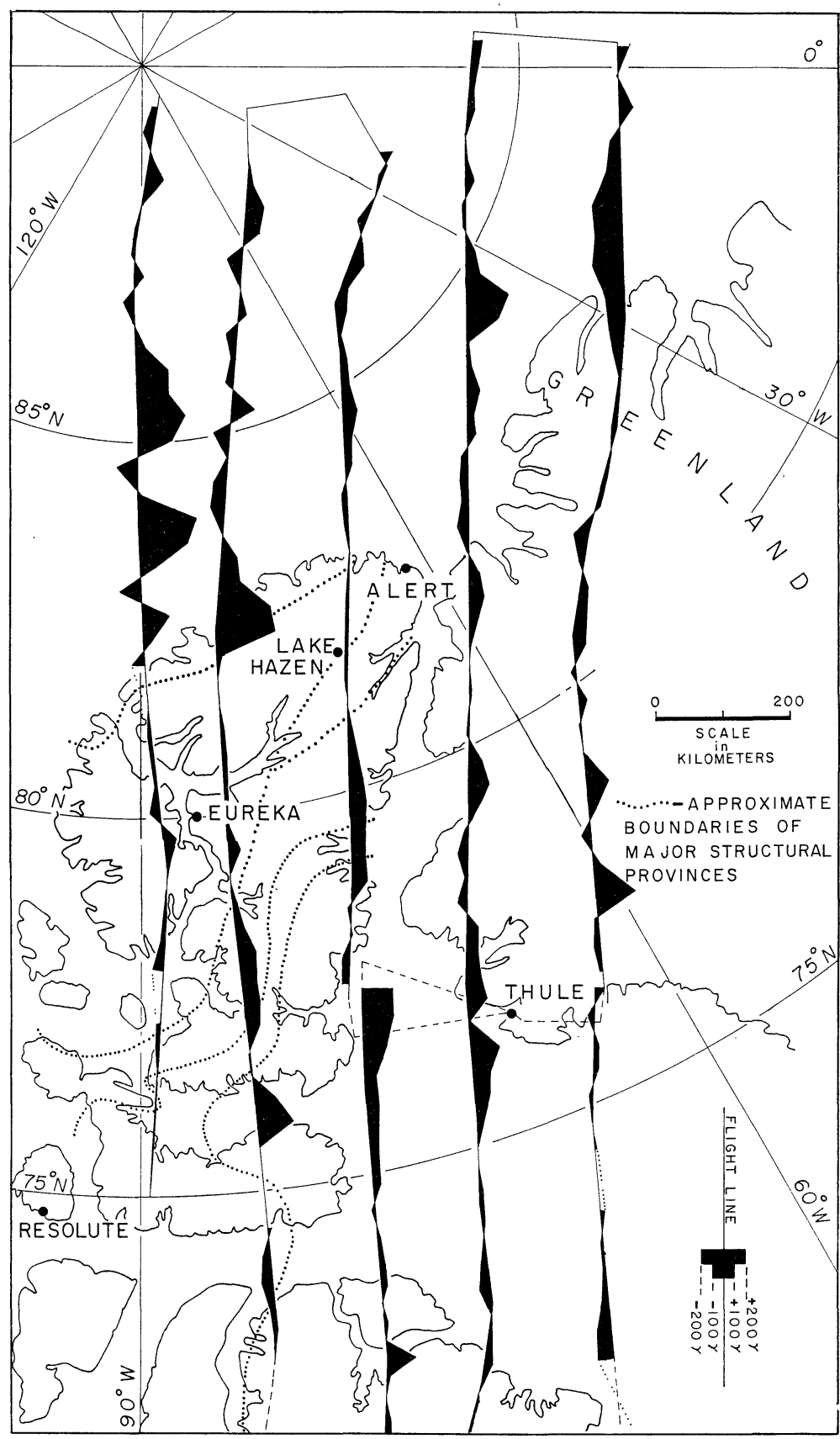

Fig. 1 Line profiles over Ellesmere Island, Canada of aeromagnetic flights of Hannaford and Haines, 1963. The 5 minute averages of the total field intensity along flight lines are shown.

Whitham and Andersen (1965) have estimated that the earlier models for Alert requiring finite but high conductivity at fairly shallow depths inside the earth cannot easily account for the measured magnetotelluric effects. Thus, for example, the diffusion of electric 
fields induced in a cylindrical structure with parameters considered relevant to the situation at Alert has been calculated to produce an electric to magnetic field ratio which decreases by a factor of ten in the period range 4 to 100 minutes, together with a phase advance of the electric field between 80 and $60^{\circ}$. At Alert therefore the situation is very puzzling since the approximate explanationgiven for the magnetic variation anomaly, and one explanation for the magneto-telluric results are not compatible. The general situation appears to be intractable. Induction over a wide area, coupling between possible underlying layers and possible surface conductors, and the influence of boundaries must all be suitably considered. However, the disappointing feature of the work at the present time is that no realistic model can be deduced which can account even extremely approximately for the magneto-telluric and the magnetic variation results. Some idea of the dilemma can be obtained by considering the question of induction in a finite horizontal sheet approximated by a flat elliptical section. It can then be shown that, even for an infinite conductivity, the magnitude of the induced field above the centre is much too small to account for the observed magnetic variation anomaly. Similarly although a deep ocean basin exists to the north, the distance to the margin is about $200 \mathrm{~km}$, and the direction of confinement of the magnetic vector at Alert is substantially different from the perpendicular to the margin. It is clear that a much more accurate determination of the frequency response of the anomaly would be useful in distinguishing between possibilities (Whitham, 1964; Whitham and Andersen, 1965). This is very difficult to do in the Arctic, since the best way of determining the frequency response accurately involves an assumption of some normal level at an appreciable distance away from the anomaly. When the scale width of an anomaly becomes some appreciable fraction of the scale length of the natural inducing fields, this becomes impossible without uncertain and extensive statistical calculations.

\section{Recent Work on the Mould Bay Anomaly in Geomagnetic Variations}

The spatial extent of the striking suppression of vertical field magnetic variations reported at Mould Bay observatory by Whitham $(1963,1964)$ has been experimentally investigated during the 1963-64 summers. Temporary stations which have been occupied are shown in Figure 2. In 1963 saturable core magnetometers were operated at the four locations very approximately $100 \mathrm{~km}$ to the north, east, south and west of Mould Bay. A new field technique was developed with moderate success, in which the saturable core magnetometers and continuously running generators were serviced every few days from the Mould Bay base camp using a light fixed wing aircraft. Additional experiments were also made a few miles from Mould Bay which confirmed that the Mould Bay effect was not a highly localized effect. In 1964, three of the same magnetometers were operated along a line between Mould Bay and Resolute Bay magnetic observatories with stations at McCormick Inlet, Sabine and Weatherall Bay on Melville Island. The latter station is some $330 \mathrm{~km}$ from Mould Bay, or approximately half way between Mould Bay and Resolute Bay magnetic observatories. The other two stations were spaced approximately $60 \mathrm{~km}$ nearer Mould Bay. At McCormick Inlet, Weatherall, and Mould Bay magneto-telluric experiments were successfully undertaken. 


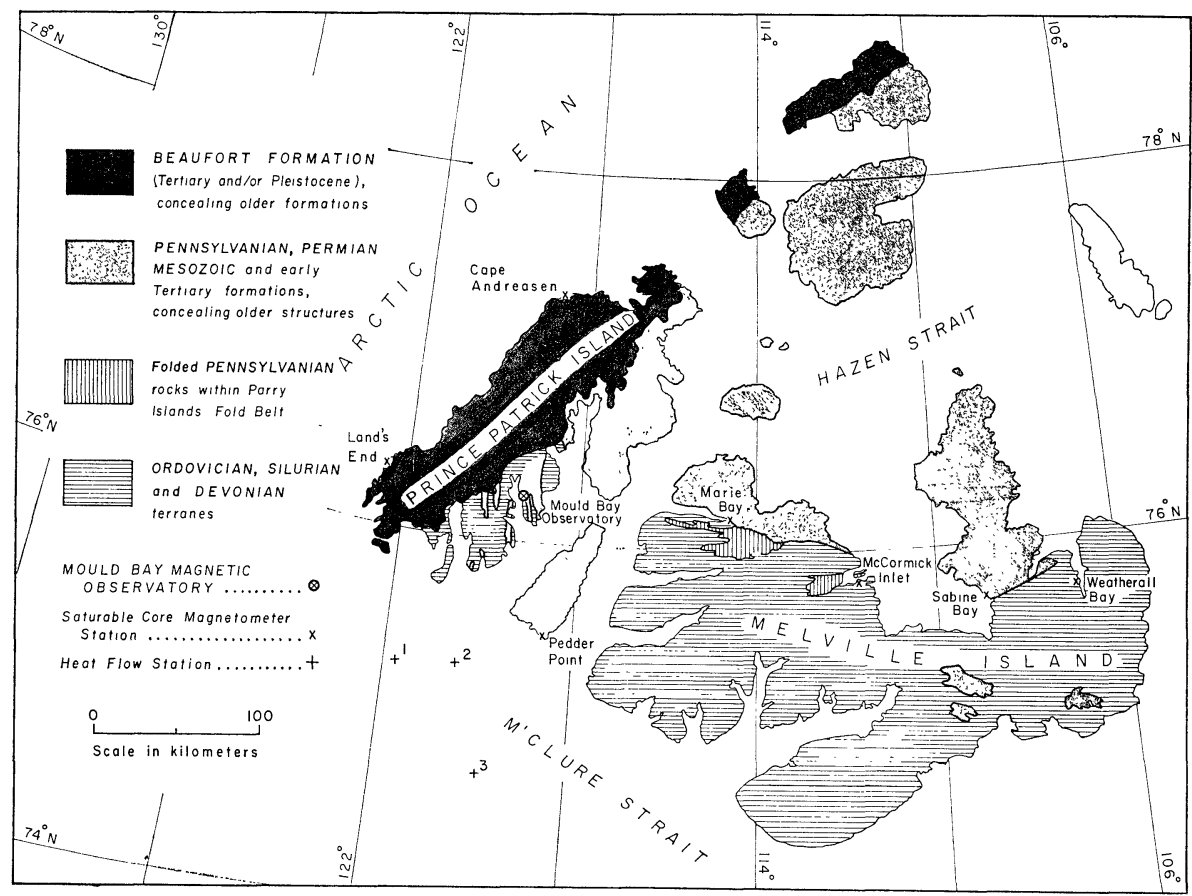

Fig. 2 Map showing positions of temporary variometer stations occupied in the Western Arctic Archipelago during 1963 and 1964. Heat flow stations in McClure Strait are also shown. The regional geology is adopted from G.S.C. Memoir 332 by Tozer and Thorsteinsson.

The results from these seven stations have been visually examined on an event basis and are now being analyzed statistically, but at the present time only the hourly range data is available to illustrate the spatial extent of the anomaly. This is shown in Figure 3 normalized to Mould Bay. The effect is appreciable reduced within a $200 \mathrm{~km}$ northsouth distance, and extends from the west side of Prince Patrick Island to about $200 \mathrm{~km}$ east of Mould Bay. The regional slopes shown in Figure 3 are derived by interpolation between Resolute Bay and Baker Lake observatories as a function of geomagnetic latitude. The difference between the 1963 and 1964 regional slopes are negligible, and the approximate reduction at Mould Bay in the hourly range in the vertical magnetic field is nearly $40 \%$. The north horizontal field range is inferred to be enhanced by some $20 \%$, and the east horizontal field roughly approximately $50 \%$. The regional interpolation is certainly subject to error, but in the summer months it is not likely to be seriously incorrect, and the close agreement of Weatherall and Sabine data supports the slopes adopted. A plot, not reproduced here, of $R_{Z} / R_{X},_{Y}$ demonstrates the regional extent of the anomaly, even more strikingly. Of course it is not possible to convert the range data to frequency plots directly.

Attempts are being made, using induction diagrams, to search for possible boundaries, though no clear magnetic field polarization is evident from visual examination of the records. The earth current results on Melville Island Indicate normal (i. e. $\sim 1 \mathrm{mV} / \mathrm{km} / \gamma$ ) electric to magnetic field ratios, which may be frequency dependent. The visual examination of the 


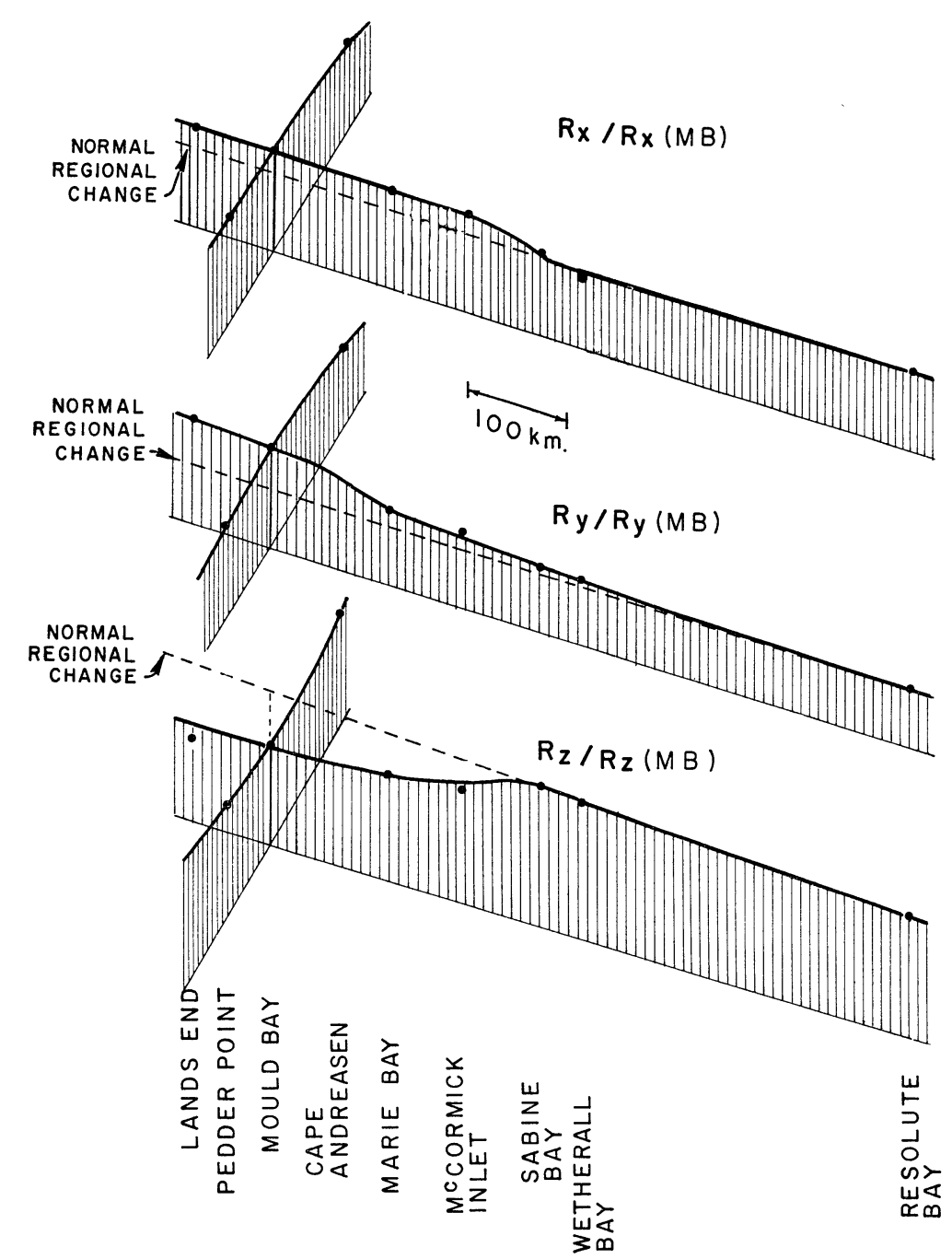

Fig. 3 Schematic diagram showing areal extent of Mould Bay effect by means of the normalized hourly range values in three orthogonal magnetic field components.

records suggests an appreciable polarization even at long periods at both locations, the directions differing by nearly $90^{\circ}$ and neither agreeing very well with the trends in the Palaeozoic formations. At Mould Bay about $200 \mathrm{~km}$ away, the electric to magnetic field ratio is strikingly reduced, being at least ten times smaller. Spectral and other analyses of these records has just commenced, and it is too early to comment on phase and any frequency dependence, but certainly any anisotropic effects appear to be less immediately evident than was the case at Alert. Induction arrows, spectral calculations, digital filtering techniques, and comparisons with the magneto-telluric results will be used in the final presentation of results.

To test the original suggestion of a large regional upwarping of the $1400-1500^{\circ} \mathrm{C}$ isotherm, producing the conductivity anomaly by ionic semi-conduction, Law, Patterson and 
Whitham (1965) measured the heat flow in M'Clure Strait between Prince Patrick Island and Banks Island in the spring of 1964. The technique used was a modification of the usual thermal probe method, used so successfully in marine geophysics, and measurements were made from the sea ice, using portable equipment carried in a fixed wing aircraft, in water depths of about $430 \mathrm{~m}$. The weighted mean heat flow for the three stations within $55 \mathrm{~km}$ of a point, some $130 \mathrm{~km}$ southsouthwest of Mould Bay, shown in Figure 2, was $0.84 \pm 0.09$ microcalories $/ \mathrm{sq} \mathrm{cm} / \mathrm{sec}$, or $57 \%$ only of the world wide continental average Whilst a number of uncertainties remain, Law et al. (1965) showed that the influence of any calculable disturbing effects do not exceed some $30 \%$, so it is clear that no anomalously high heat flow is found in this region. Consequently, in the absence of any known major perturbing effect it must be concluded that the structure responsible for the suppression of vertical magnetic field variations at Mould Bay observatory either does not extend $130 \mathrm{~km}$ to the south, is not produced by anomalously high near-surface temperatures, or is of late Quaternary origin. The measurements made at Pedder Point, Eglinton Island, some $100 \mathrm{~km}$ south of Mould Bay, have only been partially studied but it appears from the range data that although the suppression effect is reduced within this distance to the south, it has not entirely disappeared. Consequently is appears entirely possible that the earlier basic hypothesis of a temperature anomaly is fundamentally incorrect.

Christie (1963) reported that Mould Bay is underlain by moderately deformed thinbedded sandstone, siltstone, and shale of the Devonian Island formation. The thickness of sedimentary formation at Mould Bay is estimated to be in excess of $5 \mathrm{~km}$, the underlying basement rock presumably being that underlying the Franklinian geosyncline. The local geology is very complex, but no compositional explanation for a vast conductor is known. Within a radius of $60 \mathrm{~km}$ of Mould Bay, four small gravitational anomalies, two positive and two negative, appear with magnitude 10-15 mgals and typical half-widths of about 30 $\mathrm{km}$. The regional Bouguer anomaly map of the area is very complex, with small negative anomalies of 10 to $20 \mathrm{mgal}$ to the east associated with the Sverdrup Basin, and small positive anomalies of 10-20 mgals thought to be associated with the pre-Cambrian arch and its possible extension from Banks Island to southern Prince Patrick Island (the Prince Patrick uplift). Sobczak et al. (1963) suggested that the flat and broad belt of positive anomalies extending north-easterly from Prince Patrick to Axel Heiberg Islands may be associated with a basement arch, bounding the Sverdrup Basin. Again there is no very good evidence for extensive basement mineralization, particularly since two aeromagnetic profiles within 30 miles of Mould Bay published by Gregory et al. are essentially flat. Furthermore the author has recently been allowed to examine briefly the low altitude aeromagnetic flight records obtained by Canadian Aero Service Limited in this area. Once again there appears to be no evidence for extensive basement mineralization, although other interesting aspects are evident.

Seismic investigations of the Mould Bay seismograms have been made by Ichikawa and Basham (1964) in an attempt to relate certain unusual features noted on these, with the suggestion made earlier by Whitham (1963) for the vertical field suppression effect. In parti- 
cular, $\mathrm{P}$ travel-time residuals, unified magnitudes from Mould Bay seismograms and spectral analyses of the initial P-wave trains have been studied. It now appears clear that some rather unusual azimuthal-dependent effects are found. However, it has not proved possible to relate these to the cause of a magnetic variation anomaly. Furthermore it appears clear that the unusual sensitivity of the Mould Bay seismic observatory can be attributed to its low noise environment and to the effect of a resonance in a superficial layer quite near the station of perhaps $1 \mathrm{~km}$ or so thickness. Lateral variations in the superficial layer may account for the azimuthal effects which have been noted. Finally seismic investigations were conducted in 1964 in an attempt to measure the $P_{n}$ velocities in the upper mantle near Mould Bay, but the results from these explosion studies are not available.

It is clear therefore that the available seismic, gravity and aeromagnetic data fail to suggest at the present time a viable alternative to the temperature anomaly explanation, which appears discredited. Once again the geophysical significance of the data being analysed is obscure, and very puzzling.

\section{Studies in Eastern Canada}

It is important to undertake experimental work searching for possible magnetic variation anomalies in other regions of Canada. The account which follows in this section was summarized from the thesis of Rostoker (1963), and strengthened by personal communications from Garland (1964), and Niblett (1964). The stations referred to in this section are shown in Figure 4. During two months of 1963, Rostoker of the University of Toront operated four saturable core magnetometers in southern and eastern Ontario, his stations being at London, Guelph, Agincourt and Port Hope. Dominion Observatory records were available at the same time from Agincourt and Ottawa. From an analysis of 63 events with durations varying from about 3 minutes to 3 hours, Rostoker concluded that the changes in declination, horizontal and vertical field intensity variations between London and Ottawa were smooth, with the horizontal field components increasing by about $13 \%$ and the vertical field components by about $35 \%$, over a region where the mean geomagnetic latitude is near $56^{\circ}$ and increases by about 2.6 degrees. Rostoker (1963) concluded that within a confidence level of $20 \%$ no major anomalies exist. Further to the east and somewhat later, Garland maintained stations at St. Hilaire, with the cooperation of the Department of Geophysics of McGill University, and at Sherbrooke with the cooperation of the Department of Physics of the University of Sherbrooke. He reports that, comparing these stations together and against the records available from the Dominion Observatory at Ottawa, there is no evidence for any major anomaly between Ottawa and Sherbrooke, It is clear, therefore, that over a distance of $800 \mathrm{~km}$ between London and Sherbrooke, no major anomaly has been detected. Although southern Ontario is regarded as tectonically stable, faulting does occur near Ottawa, and between the Sherbrooke and St. Hilaire stations of Garland a major tectonic feature, Logan's fault occurs. This is a large thrust-fault, originating in the Devonian, which extends from southern New York State through Lake Champlain to the St. Lawrence near Montreal, and then down river to the Gulf of St. Lawrence. To the northwest the Paleozoic 


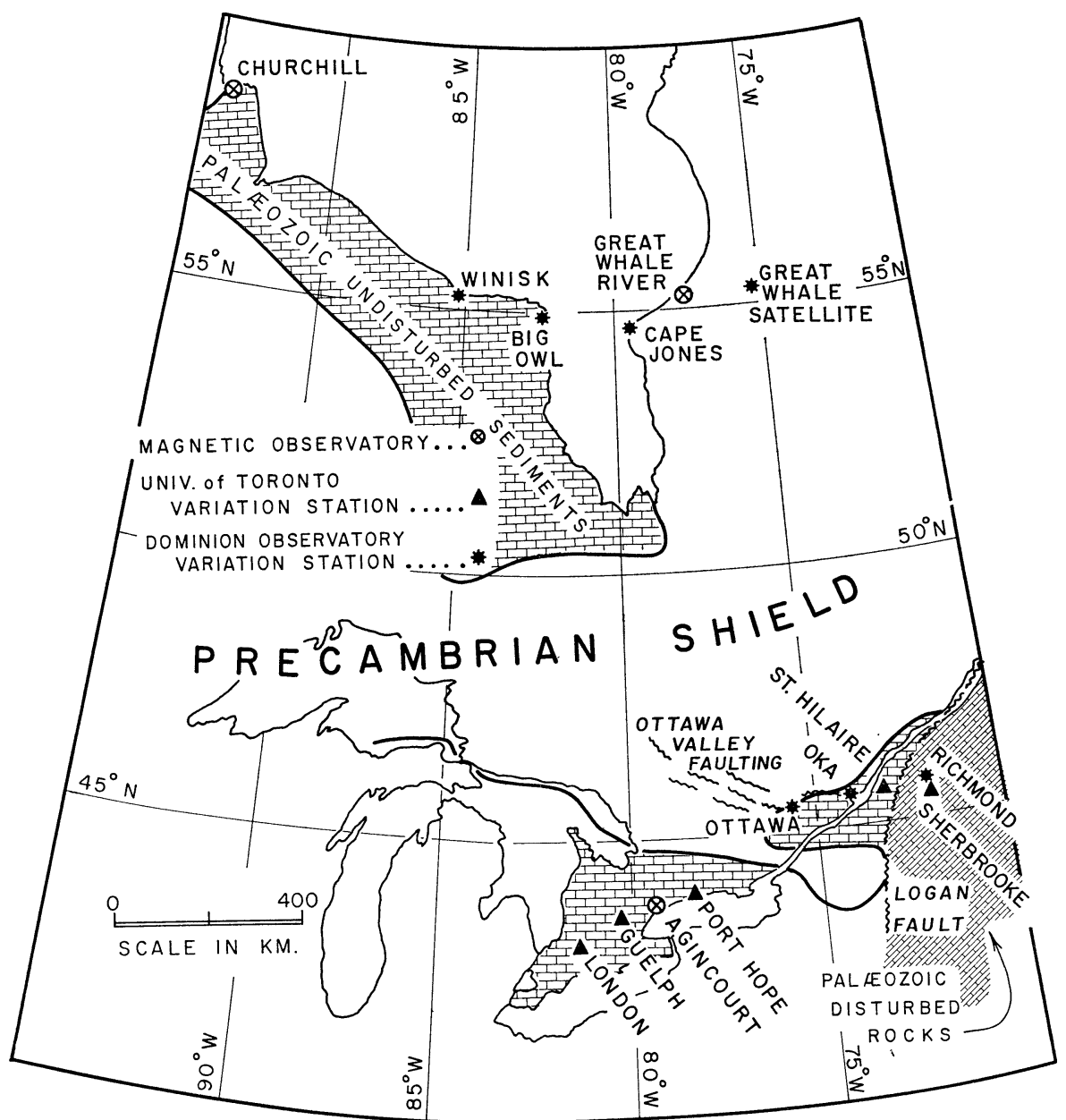

Fig. 4 Map of eastern Canada showing magnetic observatories and variation stations occupied by the University of Toronto and the Dominion Observatory during 1963 and 1964. Regional geology is outlined schematically.

formations are flat lying, while the Appalachian section on the southeast side of the fault contains highly folded and faulted strata, metamorphic sediments and igneous rocks. The important negative result of Rostoker and Garland has been confirmed by Niblett and Darker of the Dominion Observatory who, in the course of magneto-telluric investigations, have occupied stations at Richmond and Oka in western Quebec, also shown in Figure 4. Niblett reports that, from a comparison of these field records with those available in Ottawa, there is no evidence of any major magnetic variation anomaly, at least for periods exceeding afew minutes.

\section{Studies in Western Ganada}

Work on the west Coast, by the University of British Columbia group, has been more successful in discovering unusual magnetogram features. During 1963, Hyndman (1963) occupied a total of twelve field stations using four saturable core magnetometers and four 


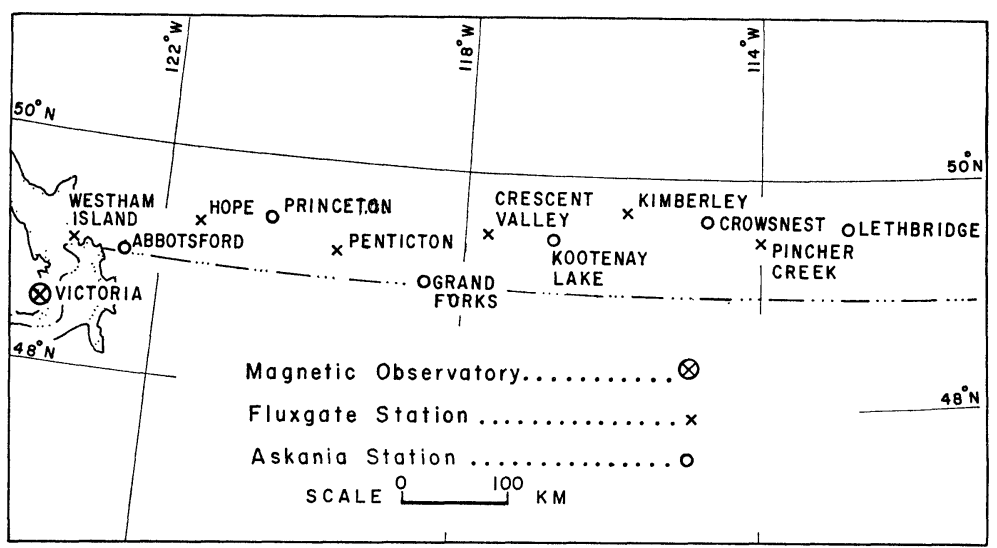

Fig. 5 Map of western Canads showing approximately east-west magnetic variometer profile of University of British Columbia, 1963. Positions taken from Hyndman, 1963.

Askania portable photographic variometers employed alternately along his profile at any one time. The field results could be compared with the records from Victoria Magnetic Observatory. Including Victoria, the line of thirteen stations formed an excellent east-west profile, shown in Figure 5, from Victoria, through Vancouver, British Columbia, to Lethbridge, Alberta, the stations being very approximately $60-80 \mathrm{~km}$ apart, and the profile being approximately perpendicular to the strike of the Canadian Cordillera.

For bay-like events with durations between 5 and 120 minutes Hyndman found that in the eastern part of his chain, between Crescent Valley and Lethbridge, the vertical field variations appeared to be anomalously large, whilst in general the horizontal field variations appeared similar to those of the stations to the west. Since the vertical components at the eastern six stations vary widely, Hyndman made some estimates assuming cylindrical twodimensional structures and treating the results for each station in isolation from the results of the anomalous stations on each side. If large bodies or boundaries are assumed to be responsible, and the horizontal field variations are considered, this theoretical simplification is rather difficult to justify, and consequently the individual estimates presented in Hyndman's thesis are not very reliable. Nevertheless the very complex pattern of vertical field variations revealed by his experimental work is extremely interesting and also rather puzzling. The direction of strike of the responsible bodies or structures is at times roughly direction of parallel to the major geological structural features and at other times almost perpendicular. No simple relation to the geological setting of the field station is apparent. For example, Crescent Valley and Grand Forks are both stations underlain by Coast Range acid intrusive rocks, yet one is anomalous whereas the other, some $80 \mathrm{~km}$ away, appears quite normal.

Because of his use of photographic variometers Hyndman was able to investigate the diurnal variations, and reported that at one site only, Crowsnest in the Canadian Rockies, a strong morning rise occurs in the vertical field diurnal variation which is not present at all the other stations. This interesting experimental discovery which would certainly be regarded as evidence for something unusual at great depth has not yet been investigated further or independently confirmed. It is clear however that entirely different results have 
been obtained along an $800 \mathrm{~km}$ east-west profile in western Canada, than from a profile of almost similar length in eastern Canada, at about the same geomagnetic latitude.

It should be mentioned that from a study of the magnetograms published in Hyndman's thesis, it would be possible to suggest that to the west of Crescent Valley, where the vertical field variations are in general smooth but of small magnitude, suppression of the vertical field variations occurs and that indeed these stations are the abnormal ones, rather than the others. If a rise of material with a conductivity of the order of $10^{-11} \mathrm{emu}$ to within about $200 \mathrm{~km}$ of the earth's surface occurs, smoothing of a form qualitatively observed could be explained. Here again, it is obvious that it is very difficult to be certain what constitutes an anomaly at latitudes just south of the auroral zone, the only clear fact being that over a distance

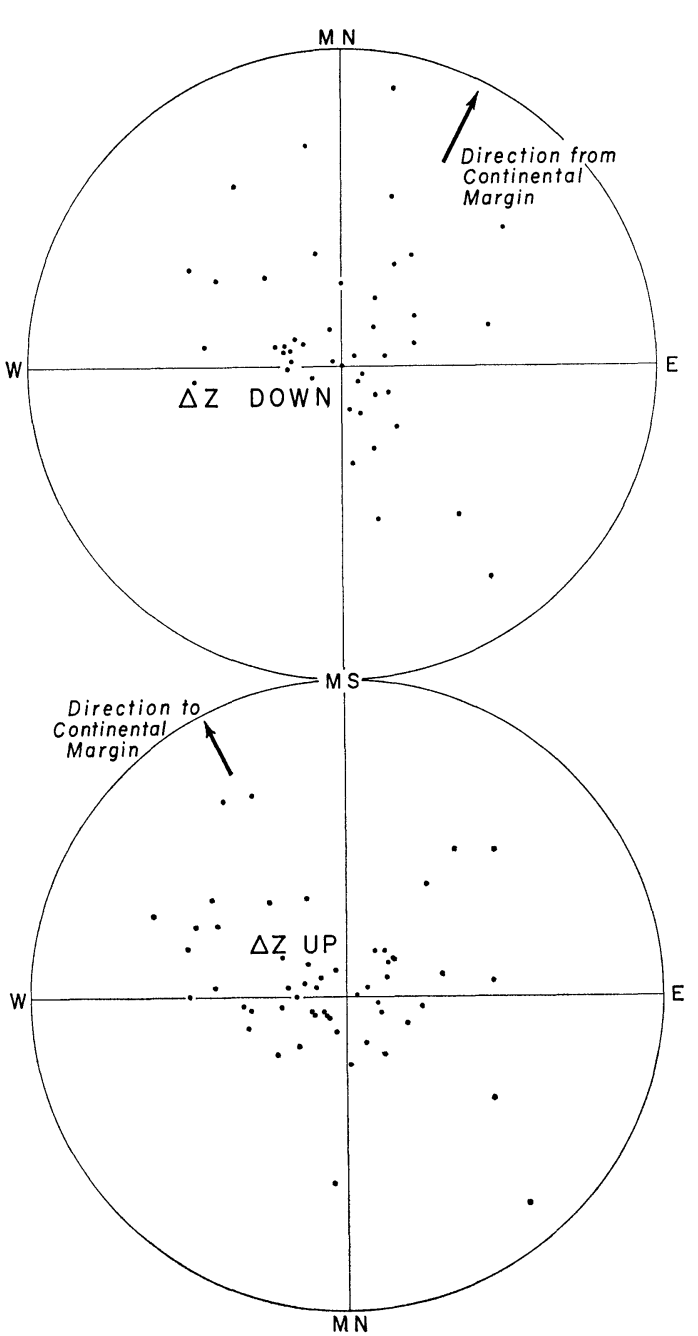

Fig. 6 Induction diagram for Victoria Magnetic Observatory. Magnetogram movements over 30 minute intervals are plotted in dip and azimuth form on polar stereographic projections. of some $800 \mathrm{~km}$ major, remarkable and reproducible differences occur in the vertical field variations. At quite close stations the vertical field variations can be correlated with entirely different horizontal field components, and it is very difficult to understand where the necessary boundaries arise, if boundary explanations are invoked, or why the horizontal field variations should be so uniform if cylindricallike conductors at depth are assumed.

For the past several months, work on the west coast of Canada, by the University of British Columbia in cooperation with the Dominion Observatory, has concentrated on a search for and the study of any possible coastal effect. Sometime ago some 100 Victoria magnetogram muvements over 30 minute intervals were plotted on dip and azimuth projections in the manner suggested by Parkinson. The points are shown in Figure 6, indicating no clear result was found. However, Lambert and Caner have now operated Askania magnetometers at Tofino on the west coast of Vancouver Island about $50 \mathrm{~km}$ from the 100 fathom line, at Franklin River on Vancouver Island about $120 \mathrm{~km}$ from the 100 fathom line, and on Westham Island and at Abbotsford airport on the main- 


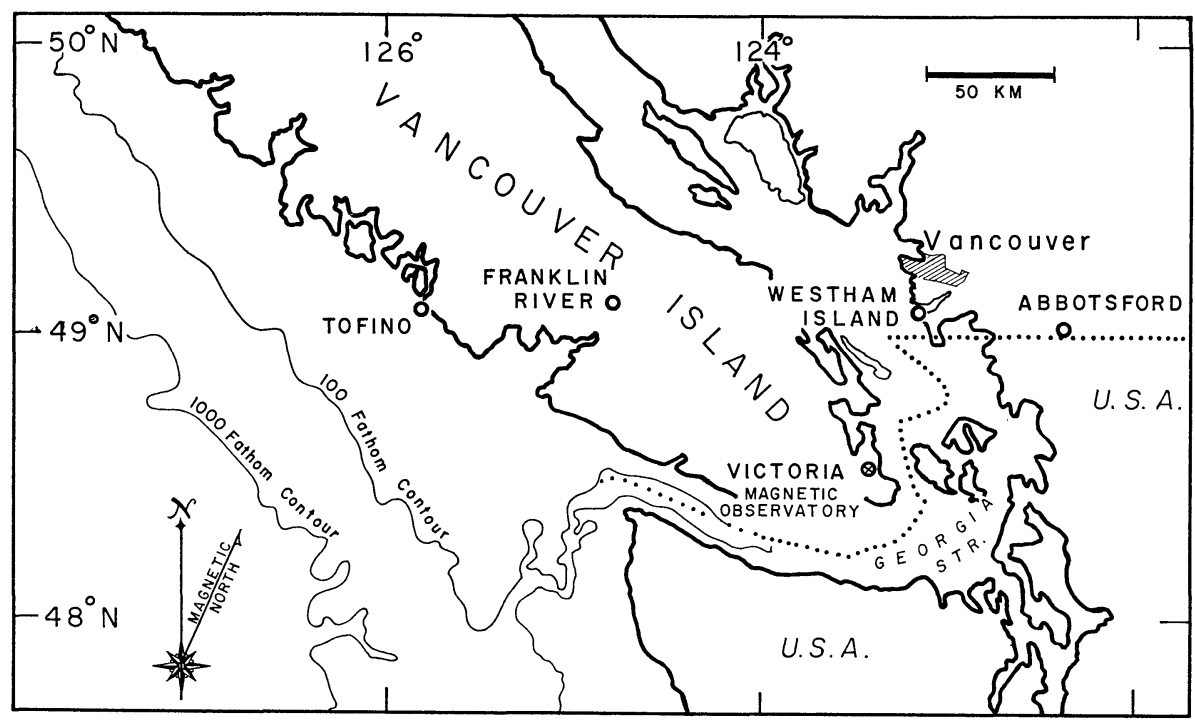

Fig. 7 Map of Vancouver Island and nearby mainland showing magnetic variometer stations of University of British Columbia and Dominion Observatory, 1964. Bathymetric contours are also shown.

land. The last two stations were used in the profile experiment of Hyndman's described above, and in this work were regarded as representative normal inland stations. Figure 7 shows the stations occupied. The records from these variographs at about 80-100 km spacing, along an east-west profile at geographic latitude $49^{\circ}$ have been compared with the records at Victoria Magnetic Observatory, about $70 \mathrm{~km}$ to the south of the profile. Tofino and Westham Island stations were operated for about six months, Franklin River for about 3 months and Abbotsford for about 1 month. Due to frequent instrument failures, mainly in the drive unit, and to some local disturbances, useful simultaneous recordings cover an effective period of about 5 weeks only. Preliminary results only have been reported by Lambert (1964) of the University of British Columbia, and Caner of the Dominion Observatory. Parkinson-tpye diagrams have been attempted, and Lambert has suggested that the correlation at Tofino changes from east-west at 1-2 cph to northeast-southwest at 2-3 cph with a very high scatter, even using Fourier cofficients from only a few events. The scatter at Victoria with this restrictive technique is very high, confirming the negative results shown in Figure 6. Off Vancouver Island, the direction of strike of the continental margin is approximately $40^{\circ}$ west of north. Since in this area the declination is about $23^{\circ}$ east of north, it would be expected that anomalous effects produced by the oceancontinent boundary would correlate most highly with field changes between 20 and $30^{\circ}$ east of magnetic north.

Lambert has used a comparison of the vertical field with declination changes along the profile to illustrate the spatial dependence: in general the ratio decreased smoothly from west to east for six features studied, the ratio at Tofino being sometimes $100 \%$ larger than at Westham Island, whereas the declination changes decrease $5 \%$ only between Westham Island and Tofino. Analysis of eight features at $3 \mathrm{cph}$ using the vertical to total horizontal field change indicates that the ratios at Westham Island and Victoria are in general larger than 
at Franklin River, but smaller than at Tofino. Inland horizontal variations may be as much as 20\% larger than at Tofino, and Lambert (1964) uses the terms "Georgia Strait" effect. Caner and Whitham conclude that adopting a confidence level of $20 \%$ it seems fair to state that only Tofino is appreciably anomalous, although a small but ill-defined secondary Georgia Strait effect may exist.

It is worth noting that the results from this study do not appear to agree with those repored by Schmucker (1964) for stations off the Californian coast to the south. Schmucker reported clear induction arrows perpendicular to the continental margin for stations at distances inland of about $200 \mathrm{~km}$. The distances to the deep ocean as defined by the 1000 fathom line are approximately $50 \mathrm{~km}$ greater than described above. Victoria observatory is about $200 \mathrm{~km}$ from the 1000 fathom line. It thus appears likely that either the sharpness of the land-sea boundary, or other deeper effects must be different. Lambert (1964) reports that the vertical daily variation for both diurnal and semi-diurnal components decreases eastwards along the profile, Tofino amplitudes being 20-30\% larger than Abbotsford. The horizontal field is slightly reduced from Abbotsford to Tofino in the semi-diurnal component and unchanged in the diurnal component.

\section{Studies in the Auroral Zone}

The only network in Canada of variometer stations useful for local inductive studies near the auroral zone existed during the late autumn of 1963, when a chain of five saturable core recording magnetometers was operated in a study of magnetic conjugacy in and around Great Whale River. The five stations, shown in Figure 4, were operated by Walker and Andersen of the Dominion Observatory, and set up at approximately equal separations along a very approximate east-west line, some $600 \mathrm{~km}$ in length. About $600 \mathrm{~km}$ east of the most westerly of Walker's stations, the permanent magnetic observatory at Churchill provided another reference point. The geomagnetic latitudes for the six stations vary by about $2^{\circ}$, the line of stations being in a region where the field sources and the electrojet patterns are known to be very changeable and very complex, with considerable latitudinal and longitudinal differentiation. It is interesting to consider the results obtained by Walker (1964) in studying the hourly range in the horizontal and vertical field components. A fairly smooth lateral variation in the hourly range is found for simultaneous data (see Figure 8). At one station only, Big Owl, the average range deviates more than 5\% from smooth curves. At Big Owl a reduction of some $24 \%$ in the interpolated vertical field hourly range is inferred. In view of the closeness to the auroral zone, it is not at all clear that this result for Big Owl represents any unusual inductive situation, particularly since an examination of different events on the records has not so far indicated any unusual features at Big Owl attributable to unusual induction. Rather, the result can be interpreted as indicating the confidence level which can be attributed to measurements of this kind in auroral zone latitudes in Canada. Alternatively the results can be expressed in terms of fluctuation about an average range. Thus for this linear index the maximum variation from an average hourly range in the horizontal field and in the vertical field did not exceed $\pm 12 \%, \pm 20 \%$ respectively, across east-west profile 


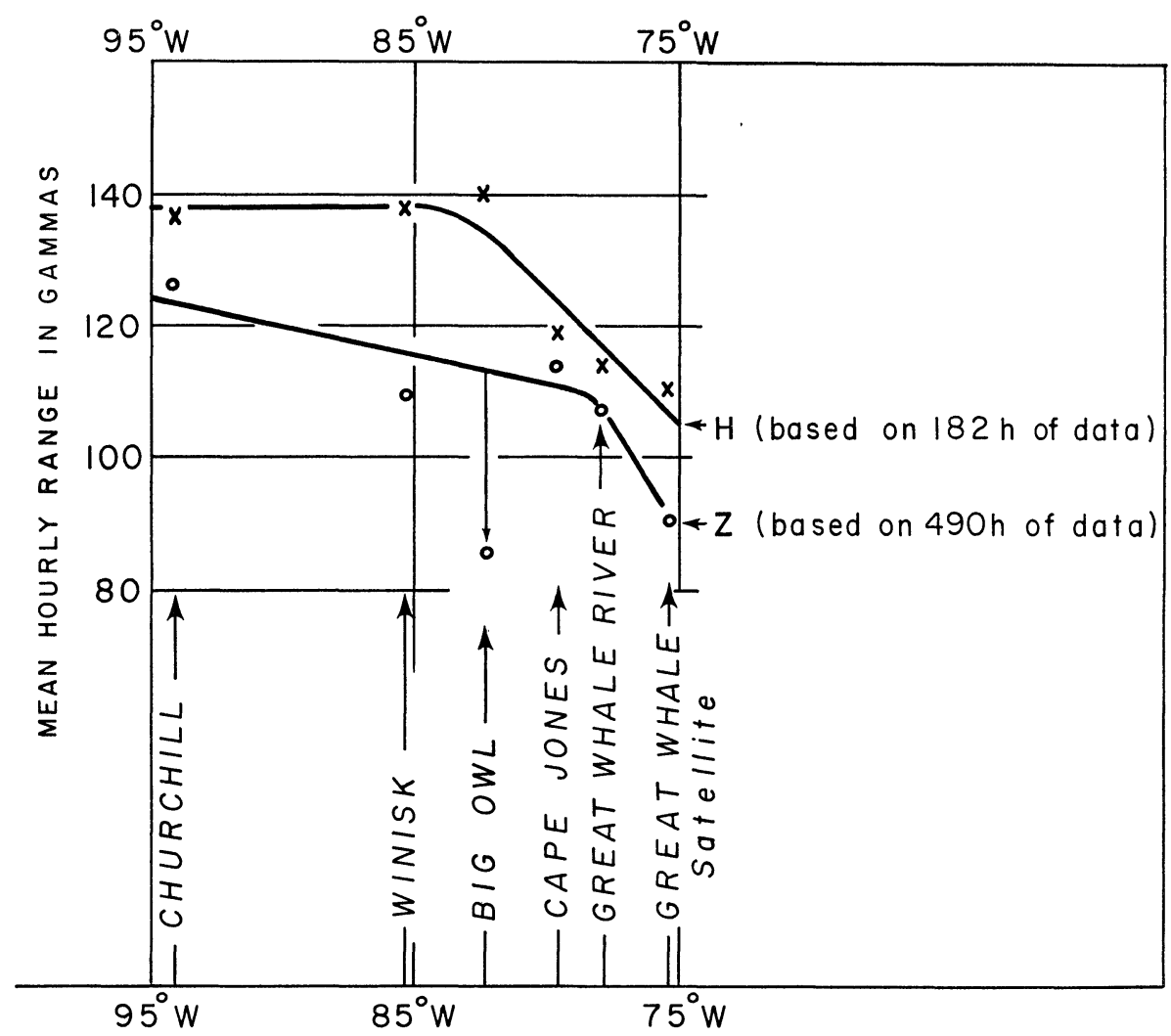

Fig. 8 Mean hourly range data in the horizontal and vertical magnetic field variations for simultaneous periods of recording for six stations distributed along the auroral zone in Canada, autumn 1963.

in auroral latitudes (average $\Phi=67^{\circ}$ ) of about $1200 \mathrm{~km}$ length. For the five field stations spread over $600 \mathrm{~km}$, the corresponding figures were $\pm 12 \%$ in horizontal field and $\pm 11 \%$ in the vertical field, at the most disturbed season of the year, It is clear that these estimates are reasonably compatible with the confidence limits adopted perforce by workers in the more southerly magnetic latitudes in Canada. The results quoted above for 182 hours of simultaneous data were confirmed using all the available data of Walker, even though more than half of this is not exactly simultaneous.

\section{Conclusions}

The Canadian experience, outlined above, suggests that unexpected inductive situations in the period range to about 100 minutes are quite likely to be found in profound geosynclinal regions. The earlier Arctic explantions appear to be either inadequate or incorrect, and at the present time the application of all available geophysical techniques to regions where clear and striking lateral variations have been discovered fails to provide a self-consistent solution either in terms of a compositional or a temperature effect. Adequate theoretical treatments for bodies of finite extent and boundary problems appear to be lacking, and magnetic variation and magneto-telluric experiments on a wider scale appear necessary. 
Recent advances in solid state saturable-core magnetomelers and miniature digital and f.m. magnetic tape systems suggest that an increase in the density of field stations by a factor of between 5 and 10 is quite possible within a few years for the same logistical and manpower support. Useful studies of the longer diurnal periods, now only possible with photographic variometers, should then be entirely feasible with the data available in convenient digital form.

The rather confusing situation now existing in Canada cannot be correlated with the regional geology, and it still appears likely that the explanation of many of the effects found must lie in the upper mantle.

\section{Acknowledgements}

I wish to thank Professor J.A. Jacobs and his graduate students, Mr.R. Hyndman and Mr. A. Lambert at the University of British Columbia, and Professor G.D. Garland and Mr. Rostoker of the University of Toronto for permission to quote from and comment on their work in this field. I also acknowledge the assistance of my colleagues Mr. J. DeLaurier, Mr. L. K. Law, Mr. F. Andersen, Mr. J. Walker, and Mr. B. Caner in this work. Dr. E.R. Niblett has very kindly reviewed the manuscript.

\section{References}

Chrsitie, R.L. Personal Communication. 1963.

Duffus, H.J., Kinnear, J.K., Shand, J.A. and Wright, C.S. Spatial Variations in Geomagnetic Micropulsations. Can. J. Phys. 40, 1133. 1962.

Garland, G.D. Personal Communication, 1964.

Hyndman, R.D. Electrical Conductivity Inhomogeneities in the Earth's Upper Mantle. M.A.Sc. Thesis, University of British Columbia, Department of Physics. 1963.

Ichikawa, M. and Basham, P. Personal Communication. 1964.

Lambert, A. Personal Communication. 1964.

Law, L.K., DeLaurier, J., Andersen, F. and Whitham, K. Investigations during 1962 of the Alert Anomaly in Geomagnetic Variations. Can. J. Phys. 41, 1868. 1963.

Law, L.K., Patterson, W.S.B. and Whitham, K. Heat Flow Determinations in the Canadian Arctic Archipelago. Can. J. Earth, Sciences, 2, 59. 1965.

Niblett, E.R. Personal Communication. 1964.

Rikitake, T., and Whitham, K. Interpretation of the Alert Anomaly in Geomagnetic Variations. Can. J. Earth Sciences, 1, 35. 1964.

Rostoker, G. Low Frequency Variations in the Earth's Magnetic Field and their Relation to the Conductivity of the Upper Mantle. M.A. Thesis, University of Toronto, Department of Physics. 1963.

Schmucker, U. Anomalies of Geomagnetic Variations in the Southwestern United States. J. Geom. Geoel., 15, 193. 1964.

Sobczak, L.W., Weber, J.R., Bisson, J-L. and Goodacre, A.K. Gravity Map Series of Dominion Observatory, Nos. 12-15. 1963.

Walker, J.K. Personal Communication. 1964.

Whitham, K. and Andersen, F. The Anomaly in Geomagnetic Variations at Alert in the Arctic Archipelago of Canada. Geophys. J.R.A.S., 7, 220. 1962.

Whitham, K. An Anomaly in Geomagnetic Variations at Mould Bay in the Arctic Archipelago of Canada. Geophys. J.R.A.S., 8, 26. 1963. 
Whitham, K. Anomalies in Geomagnetic Variations in the Arctic Archipelago of Canada. J. Geom. Geoel. 15, 227. 1964.

Whitham, K. and Andersen, F. Magneto-telluric Experiments in North Ellesmere Island. To be published in Geophys. J.R.A.S. 1965. 